Article

\title{
Considerations on Applying the Method for Assessing the Level of Safety at Work
}

\author{
Costica Bejinariu ${ }^{1}$, Doru-Costin Darabont ${ }^{2}$, Elena-Raluca Baciu ${ }^{3}$, Iuliana-Silvia Georgescu ${ }^{1}$, \\ Mihai-Adrian Bernevig-Sava ${ }^{1}$ and Constantin Baciu ${ }^{1, *}$ \\ 1 Department of Materials Engineering and Industrial Safety, Gheorghe Asachi Technical University of Iași, \\ 67 Dimitrie Mangeron Blvd, Iasi 700050, Romania; costica.bejinariu@tuiasi.ro (C.B.); \\ sgeorgescu@tuiasi.ro (I.-S.G.); mihaibernevig@tuiasi.ro (M.-A.B.-S.) \\ 2 National Research and Development Institute on Occupational Safety-INCDPM "Alexandru Darabont" \\ Bucharest, 35A Ghencea Blvd., Bucharest 061692, Romania; office@inpm.ro \\ 3 Faculty of Dental Medicine, Grigore T. Popa University of Medicine and Pharmacy Iasi, 16 Universitatii St., \\ Iasi 700115, Romania; elena.baciu@umfiasi.ro \\ * Correspondence: constantin.baciu@tuiasi.ro; Tel.: +40-744-595431; Fax: +40-232-225986
}

Received: 28 April 2017; Accepted: 14 July 2017; Published: 18 July 2017

\begin{abstract}
The application of the method for assessing the level of safety at work starts with a document that contains the cover page, the description of the company (name, location, core business, organizational chart etc.), description of the work system, a detailed list of its components, and a brief description of the assessment method. It continues with a Microsoft Excel document, which represents the actual application of the method and, finally, there is another document presenting conclusions, proposals, and prioritizations, which leads to the execution of the Prevention and Protection Plan. The present paper approaches the issue of developing the Microsoft Excel document, an essential part of the method for assessing the level of safety at work. The document is divided into a variable number of worksheets, showing the risk categories of general, specific, and management.
\end{abstract}

Keywords: general risks; health and safety management risks; health and safety at work; safety level; specific risks

\section{Introduction}

The method for assessing the level of safety at work has been developed by Alexandru Darabont of the National Research Institute for Labour Protection, Bucharest, and was presented in the "Guide for Assessing Safety at Work" [1]. It analytically assesses the level of safety at each workplace and throughout the company before accidents occur, including both a qualitative and quantitative approach. The method covers all types of workplaces including fixed, evolutional, and mobile [2,3].

In any work system, four specific components are involved: executor, workload, means of work/work equipment, and work environment of the workplace/workstation; these components are in a permanent state of interdependence [4-6]. Each work system component may generate dysfunctions leading to accidents and occupational diseases [7,8]. Occupational accidents and illnesses are the consequence of one or more dysfunctions, caused by an initial and a final cause $[9,10]$. An occupational accident and/or illness occur(s) when there is interaction between a final cause pertaining to the means of work or the working environment and a cause related to the executor $[11,12]$. There is a biunivocal relation between causes and prevention measures. Furthermore, for each cause, there is a corresponding optimal prevention measure which, if applied, will avert the accident [13]. 
This is merely one of the assessment methods that are applicable to industrial practice, as it is well-known that any work safety assessment has a high degree of subjectivity due to both the dynamics of industrial processes and the diversity of work system components.

Given the fact that almost the entire national health and safety legislation system is in accordance with the provisions of the European directives, the system aims to develop new approaches to meet the occupational health and safety minimum requirements. At the same time, the national legislation system requires an enhancement in developing policies concerns, to make management decisions in order to identify hazards, to supervise them, to maintain measures, and to continually improve the safety level within a work system.

The principle of the method consists of analyzing the extent to which potential causes of workplace accidents and/or occupational diseases are covered by adequate preventive measures, called safety barriers. The method of assessing the level of safety at work involves identifying and evaluating, through direct visual observations and simple measurements, the existence of prevention measures specified by the legislation in force, for each hazard that exists or may occur in the work system components.

Continuing from this introduction, the paper is structured as follows: Section 2 describes the method of assessing the level of safety at work, and the way to cover all possible hazards and risks. When a risk is identified, the evaluation begins with analyzing the possibilities of combating the risk at source. Section 3 is dedicated to applying the method of assessing the level of safety at work with the help of Microsoft Office, knowing that, at present, this package is the software most commonly installed on most personal computers, on tablets, and even on smartphones, regardless of the operating system. Section 4 takes into consideration the average level of safety of the analyzed workplace, which allows for the determination of the preventive measures in ascending order of priority. Finally, Section 5 draws conclusions and presents recommendations for elaborating the Prevention and Protection Plan.

\section{Assessment Method}

Assessing the level of safety at work should cover all possible hazards and risks. When a risk is identified, the evaluation begins with analyzing the possibilities of combating the risk at source. The method of assessing the level of safety at work has the following phases: identification of hazards, identification of workers exposed to the hazards, qualitative and quantitative risk estimation, and analysis of the possibilities of eliminating or reducing risk.

Applying the assessment method involves covering the methodology described below [1].

In the first stage, the structure of the assessment plan is set out in accordance with the following phases:

- $\quad$ establishing the programme for assessing the level of safety at work;

- structuring the assessment-decisions regarding the approach;

- collecting information-on the work environment, technical equipment, workload, past experience;

- identifying hazards;

- identifying people at risk;

- identifying type of risk exposure;

- evaluating risks;

- analyzing different options of eliminating or mitigating risks-prioritising action points and protective measures;

- implementing protective measures;

- documenting and issuing the assessment;

- measuring the effectiveness of implementing the protective measures;

- carrying out a reassessment if changes occur;

- devising a work safety appraisal monitoring programme. 
In the second stage, general information about the company's activities is gathered, namely:

- field of activity, territorial distribution, size, total number of employees;

- the ratio of employees in production functions to employees with management/administration responsibilities;

- the presence of normative acts for work safety;

- how the prevention activities in regard to occupational accidents and illnesses is organized;

- the statistics on accidents and occupational illnesses;

- the results and recommendations from previous assessments or audits.

The next stage involves the delimitation and characterization of the object to be assessed-enterprise, sector, section, workshop, job—on the four components of the work system:

- executer-details on job, required qualification, seniority, coordination/subordination relationships;

- workload-detailed description of operations, methods, and pace of work;

- means of work/work equipment-description of parameters, mode of operation, raw materials, handling, storage, energy used for machines, installations, machinery, devices used in the workplace, access ways;

- work environment of the workplace/workstation-description of microclimate conditions, ventilation, lighting, noise, special conditions, etc.

For each component, specified standards, instructions, and other regulatory documents will be observed. When the object of the assessment is complex, i.e., a workshop, department, or sector, the delimitation should include: activities undertaken—goods, works, services; objective location; number of similar workplaces; number and structure of staff-jobs, qualifications etc.; technologies used-operations, equipment, raw materials, etc.; movement of personnel, materials, and finished products; lifting and transportation means; working conditions and environment; work safety laws; and lastly, special requirements.

The present paper continues with the selection of hazards referring to: the identification of workers exposed to hazards; qualitative or quantitative estimation of risks; and avoiding, mitigating, or combating the risks at source.

The identification of risks is performed by:

- observing and ascertaining working conditions at each workplace-means of access, floor state, safety of technical equipment, presence of dust, smoke, temperature, lighting, air flow, noise etc.;

- identifying work tasks and analyzing ways of working;

- analyzing the impact of external factors on the workplace-for example, weather factors;

- analyzing the impact of psychological, social, and physical factors that can induce stress;

- $\quad$ analyzing hazards induced by work equipment, installations, machinery, devices.

The findings are compared to the health and safety at work criteria set by the laws, regulations, and standards currently in force, and the existing or possible risks are then estimated. Of course, regardless of the method employed, one cannot assume an exhaustive identification of risks; furthermore, it is important to note that even the ones identified are quantified with some degree of subjectivity.

After being identified, the risks are ranked and the prevention measures are prioritized, taking into account: avoidance or mitigation of risks by changing dangerous elements with non-hazardous or less dangerous ones; combating the risks at source; determining the priority of collective protection measures-exposure to smoke, emissions, radiation, etc.

Within the assessment, the risks must be ranked according to their severity, reflected by the consequences for the human body. Therefore, risks can be minor-producing temporary inability to 
work for less than three days; significant—producing temporary inability to work for at least three days; major (critical)—leading to disability or death.

This ranking of work capacity is developed by the Romanian Ministry of Health together with the Ministry of Labour and Social Justice. By knowing the types of lesions and injuries associated with occupational accidents and diseases, it is possible to evaluate for each risk factor the lesion it will lead to, which organ will be affected and, thus, the type of consequence that it will produce: temporary inability to work, disability, or death.

For an accurate assessment of the safety level and the establishment of adequate preventive measures, the number of people at risk and the duration of the exposure must be considered. Thus, an exposure of up to $30 \mathrm{~min}$ a day is considered accidental, an exposure between $30 \mathrm{~min}$ and $4 \mathrm{~h}$ a day is considered temporary, and an exposure of over $4 \mathrm{~h}$ a day is considered permanent.

After ranking, depending on the exposure and the severity, risks can be divided into two groups: acceptable and unacceptable.

The method for assessing the level of safety at work has three sets of checklists: checklists for "General Risks" (17 checklists-I. Lighting; II. Noise; III. Vibrations; IV. Thermal environment; V. Chemical agents; VI. Carcinogens and mutagens; VII. Biological agents; VIII. Industrial ventilation; IX. Equipment; X. Workplace design; XI. Workspace design; XII. Fires and explosions; XIII. Electro safety; XIV. Work task; XV. Circulation, horizontal and vertical risks; XVI. Collective and individual protection; XVII. First aid); checklists for "Specific Risks" (a number of " $\mathrm{n}$ " checklists); checklists for "Assessment of Occupational Health and Safety Management" (five checklists-A. Management involvement; B. Strategy, plans, procedures; C. Employee consultation; D. Identification, assessment, and prevention of risks; E. Coaching, training, specialization of personnel in health and safety propaganda). Each checklist contains a brief presentation of the risk, questions that allow for the characterization of the risk, and qualitative and/or quantitative information on each specific risk. As an example, Table 1 shows Checklist I. Lighting. 
Table 1. Checklist I. Lighting [1].

\begin{tabular}{|c|c|c|c|c|c|c|c|c|}
\hline \multirow{3}{*}{ Code } & \multirow{3}{*}{ Indicators } & \multicolumn{6}{|c|}{ Awarded Score } & \multirow{3}{*}{$\begin{array}{l}\text { Weighting } \\
\text { Coefficient }\end{array}$} \\
\hline & & \multicolumn{2}{|c|}{ Unsatisfactory } & \multicolumn{2}{|c|}{ Medium } & \multicolumn{2}{|c|}{ Very Good } & \\
\hline & & 0 & 1 & 2 & 3 & 4 & 5 & \\
\hline I.1 & $\begin{array}{l}\text { Were lighting conditions subject to review by the } \\
\text { department or production unit? }\end{array}$ & & & & & & & 2.0 \\
\hline I. 2 & $\begin{array}{l}\text { Does the level of workplace lighting meet the work } \\
\text { task requirements? }\end{array}$ & & & & & & & 1.0 \\
\hline I.3 & $\begin{array}{l}\text { Do employees complain of eyestrain (punctures, } \\
\text { tearing)? }\end{array}$ & & & & & & & 1.5 \\
\hline I.4 & $\begin{array}{l}\text { Are light sources or their reflections visible in the } \\
\text { center of the workplace visual field? }\end{array}$ & & & & & & & 1.0 \\
\hline I.5 & Have measures been taken to avoid areas of shade? & & & & & & & 1.0 \\
\hline I.6 & $\begin{array}{l}\text { Does the lighting system correspond to the } \\
\text { workplace characteristics? } \\
\text { - uniform general lighting is used where similar } \\
\text { activities are performed all over the surface of } \\
\text { the room or when the position of the } \\
\text { workplace or the position of the employee } \\
\text { frequently changes during work; } \\
\text { local general lighting is used for workplaces } \\
\text { that need different lighting levels and the use } \\
\text { of local lighting is not possible; } \\
\text { combined lighting is used for workplaces that } \\
\text { need different lighting levels and the use of } \\
\text { general lighting cannot ensure adequate } \\
\text { quality requirements; }\end{array}$ & & & & & & & 2.0 \\
\hline I.7 & $\begin{array}{l}\text { Can employees individually change their } \\
\text { workplace lighting, according to the precision of the } \\
\text { task they must undertake? }\end{array}$ & & & & & & & 1.0 \\
\hline
\end{tabular}

Table 1. Cont.

\begin{tabular}{|c|c|c|c|c|c|c|c|c|}
\hline \multirow{3}{*}{ Code } & \multirow{3}{*}{ Indicators } & \multicolumn{6}{|c|}{ Awarded Score } & \multirow{3}{*}{$\begin{array}{l}\text { Weighting } \\
\text { Coefficient }\end{array}$} \\
\hline & & \multicolumn{2}{|c|}{ Unsatisfactory } & \multicolumn{2}{|c|}{ Medium } & \multicolumn{2}{|c|}{ Very Good } & \\
\hline & & 0 & 1 & 2 & 3 & 4 & 5 & \\
\hline I. 8 & $\begin{array}{l}\text { Can employees easily receive information necessary } \\
\text { for completing their tasks? }\end{array}$ & & & & & & & 1.5 \\
\hline I.9 & $\begin{array}{l}\text { Are the work tasks causing visual system strain } \\
\text { made by the same employees? }\end{array}$ & & & & & & & 1.0 \\
\hline I.10 & $\begin{array}{l}\text { Are errors, defects, scrap more frequent at the end } \\
\text { of the work shift/week? }\end{array}$ & & & & & & & 0.5 \\
\hline I.11 & Are scheduled breaks observed during the shift? & & & & & & & 1.0 \\
\hline I.12 & Is the artificial lighting system always working? & & & & & & & 1.5 \\
\hline I.13 & $\begin{array}{l}\text { Is regular cleaning of the windows provided (to } \\
\text { ensure natural lighting)? }\end{array}$ & & & & & & & 1.0 \\
\hline I.14 & Is there an emergency lighting system? & & & & & & & 1.0 \\
\hline $\mathrm{I} .15$ & $\begin{array}{l}\text { After making some changes in the lighting system, } \\
\text { has the lighting level been checked? }\end{array}$ & & & & & & & 2.0 \\
\hline
\end{tabular}

Each checklist describes, at the beginning, a source of potential adverse effects on people's health, on their activity during working hours, on the production process, as well as the general principles of prevention. The checklist contains a number of indicators, in the form of questions. Depending on the specific conditions of the workplace, the evaluator awards a score between 0 and 5. For the indicators that are irrelevant to the analyzed workplace, the checklist boxes are marked with "not applicable". Each indicator has a certain importance in terms of severity and frequency of workplace accidents or occupational diseases, so it is affected by a weighting coefficient, with values 
between 0.5 and 2.0, according to the guidelines for assessing work safety [1] developed by Alexandru Darabont of the National Research Institute for Labour Protection, Bucharest.

For each indicator, the real score is obtained by multiplying the score awarded by the weighting coefficient. Finally, each checklist calculates, by addition, the actual total score obtained, the maximum possible score, and the level of safety. Depending on the level of safety obtained for each checklist, appropriate ratings are assigned. For all checklists, there is an average level of safety.

The obtained safety level allows one to establish preventive measures, in ascending order of priority, by filling a summary sheet containing all the risks for each workplace and a summary sheet containing joint risks for each workroom, department, or production unit.

\section{Results Obtained by Applying the Method for Assessing the Level of Safety at Work Using Microsoft Office}

Microsoft Office has become the most commonly installed software on most personal computers, tablets, and even smart phones, regardless of the operating system. As a result, this software is well known and widely used by operators of these devices.

The application of the method for assessing the level of safety at work starts with a Microsoft Word document, containing the cover page, the description of the company (name, location, core business, organizational chart etc.), a description of the work system, a detailed list of its components, and a brief description of the self-assessment method. It continues with a Microsoft Excel document, that is the actual application of the method and, finally, another Microsoft Word document that presents conclusions, proposals, and prioritizations. These lead to the execution of the Prevention and Protection Plan, in accordance with the Romanian Government Decision no. 1425 of 2006, section no. 7, annex no. 7.

The present paper approaches the development of the Microsoft Excel document, an essential part of the method for assessing the level of safety at work. The document is divided into a variable number of worksheets, hereafter denoted as follows:

- "NS Ratings", worksheet containing possible ratings assigned to the safety level of each checklist, for "General Risks", "Specific Risks", and "Assessment of Occupational Health and Safety Management";

- Seventeen worksheets-“I-Lighting", "II-Noise", "III-Vibrations", etc., corresponding to the "General Risks" section;

- " $\mathrm{n}$ ” worksheets—“RS_001", "RS_002" etc., corresponding to the "Specific Risks" section;

- Five worksheets—“Checklist A", "Checklist B", etc., corresponding to the section "Assessment of Occupational Health and Safety Management".

The first column of the worksheet "NS Ratings", Figure 1-as per the guidelines for assessing work safety [1] developed by Alexandru Darabont of the National Research Institute for Labour Protection, Bucharest, contains values for each possible safety level; the second column contains the corresponding rating from "Excellent" to "Unsatisfactory"; and the third column contains the symbols for each rating. In setting the appropriate rating for each checklist, one should refer to this worksheet, so that it appears first in the Microsoft Excel document.

The worksheets corresponding to the sections: "General Risks", "Specific Risks", and "Assessment of Occupational Health and Safety Management" have the same structure and differ only in terms of "Criteria" and "Indicators", which leads us to the analysis of one of the worksheets, e.g., "Lighting". 


\begin{tabular}{|c|c|c|c|}
\hline 4 & A & B & C \\
\hline 1 & & & \\
\hline 2 & & & \\
\hline 3 & \multicolumn{3}{|c|}{ METHOD FOR ASSESSING THE LEVEL OF SAFETY AT WORK } \\
\hline 4 & & & \\
\hline 5 & & & \\
\hline 6 & \multicolumn{3}{|c|}{ Ratings for the safety level, $\mathrm{N}_{\mathrm{si}}$} \\
\hline 7 & & & \\
\hline 8 & Percent & Rating & $\begin{array}{l}\text { Rating } \\
\text { symbol }\end{array}$ \\
\hline 9 & Greater than $90, \mathrm{~N}_{\mathrm{Si}}>90$ & Safety level, Excellent & (E) \\
\hline 10 & Greater than 80 and less than or equal to $90,80<\mathrm{N}_{\mathrm{si}}<=90$ & Safety level, Very good & (VG) \\
\hline 11 & Greater than 70 and less than or equal to $80,70<\mathrm{N}_{\mathrm{si}}<=80$ & Safety level, Good & (G) \\
\hline 12 & Greater than 60 and less than or equal to $70,60<\mathrm{N}_{\mathrm{si}}<=70$ & Safety level, Medium & $(\mathrm{M})$ \\
\hline 13 & Greater than 50 and less than or equal to $60,50<\mathrm{N}_{\mathrm{si}}<=60$ & Safety level, Small & (S) \\
\hline 14 & Less than or equal to $50, \mathrm{~N}_{\mathrm{si}}<=50$ & Safety level, Unsatisfactory & $(\mathrm{U})$ \\
\hline \multicolumn{4}{|l|}{15} \\
\hline 16 & & & \\
\hline
\end{tabular}

Figure 1. "NS Ratings" Worksheet.

The worksheet "I-Lighting", Figure 2, contains in the top left corner information concerning the workplace, and in the upper right corner information concerning the assessor or the assessment team. At the same time, the worksheet contains the heading "Criteria", detailing the legislation used, in this case for the worksheet "I-Lighting". 


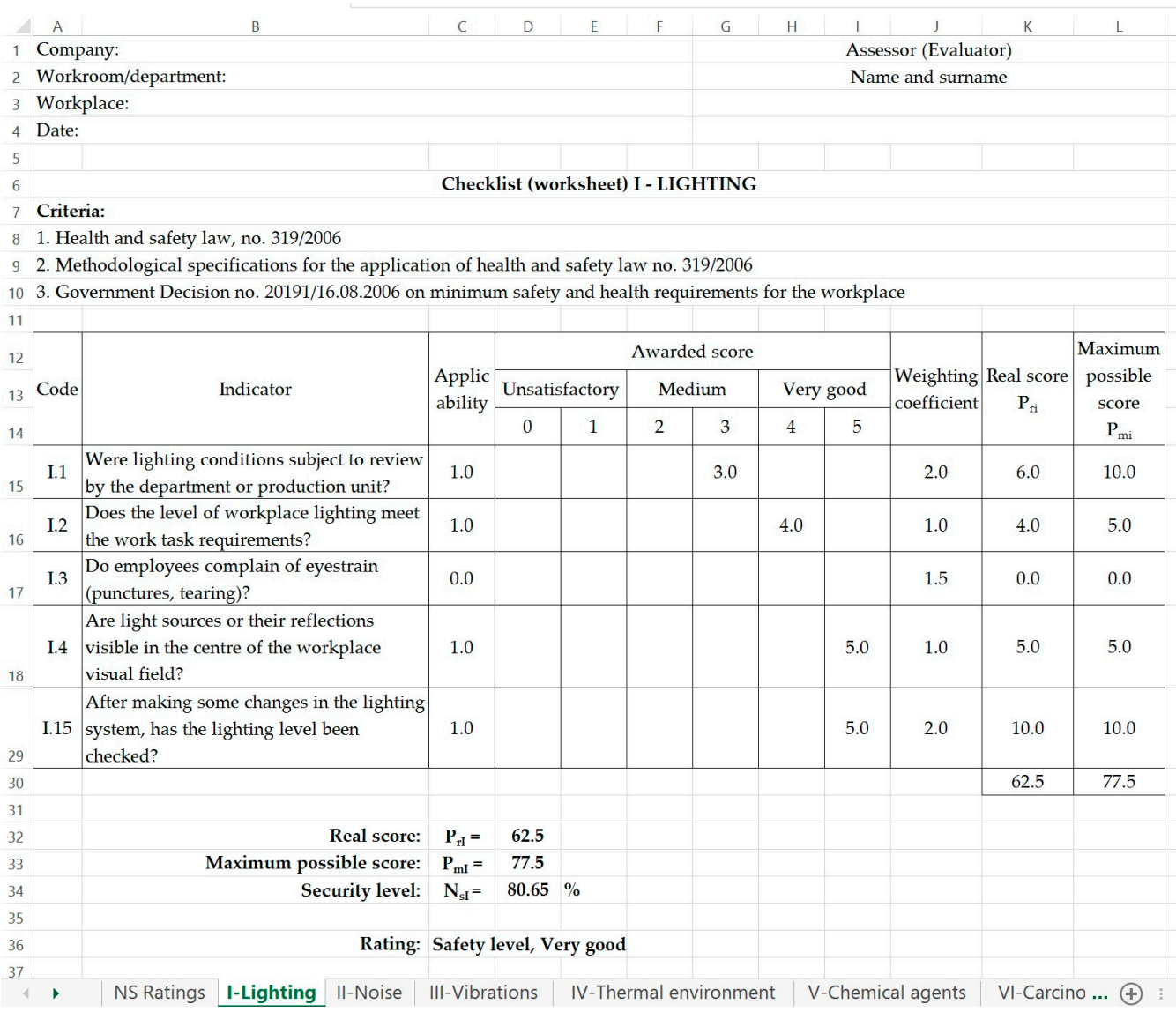

Figure 2. Worksheet "I-Lighting".

Column " $\mathrm{A}$ " refers to the number of the indicator, for example, "I.1" is the indicator " 1 " in the worksheet "I". Figure 2 presents, for simplicity, only the first four indicators "I.1"-“I.4" and the last one "I.15", the others are hidden.

Column "B" explicitly presents the indicators in the form of questions. Depending on the specific situation of the workplace, the assessor awards a score for each question.

For the indicators relevant to the analyzed workplace, the " $\mathrm{C}$ " column assigns the value 1.0 for applicability and for the irrelevant indicators, the value 0.0 , representing the non-applicability of the indicator.

The columns " $\mathrm{D}$ "- "I" are allocated to the awarded score. Depending on the workplace specific conditions, the assessor gives a score between 0.0 and 5.0:

- unsatisfactory, 0.0 and 1.0;

- $\quad$ medium, 2.0 and 3.0;

- $\quad$ very good, 4.0 and 5.0.

For example, the score " 0.0 " is granted when there is no evidence that the workplace conditions meet the indicator requirement and the score " 5.0 " is given when there is clear evidence on meeting the indicator requirement. Scores " 0.0, " "1.0", and " 2.0 " correspond to situations of non-compliance with legal requirements.

Each indicator has a certain importance in terms of severity and frequency of workplace accidents or occupational diseases, so it is affected by a weighting coefficient, with the discrete values " 0.5 ," "1.0," "1.5", and "2.0" assigned in the "J" column. 
Column "K" shows the "real score" of the indicator, noted $\mathrm{P}_{\mathrm{ri}}$. It is obtained by multiplying the score awarded by the weighting coefficient. The result is affected by the applicability value. In this case, for example, to determine the real score of the "I.1" indicator, in cell "K15" we apply the equation:

$$
=\mathrm{C} 15 \times(\mathrm{SUM}(\mathrm{D} 15: \mathrm{I} 15)) \times \mathrm{J} 15
$$

thus obtaining $\mathrm{P}_{\mathrm{ri}}=6.0$.

Column " $\mathrm{L}$ " calculates the "Maximum possible score" of the indicator, noted $\mathrm{P}_{\mathrm{mi}}$. It is obtained by multiplying the maximum score, " 5.0 ", by the weighting coefficient. The result is affected by the applicability value. In this case, for example, to determine the maximum possible score of the "I.1" indicator, in cell "L15" we apply the formula:

$$
=\mathrm{C} 15 \times 5 \times \mathrm{J} 15
$$

thus obtaining Pmi $=10.0$.

In columns " $\mathrm{K}$ " and " $\mathrm{L}$ " of the worksheet "I-Lighting", after the last indicator from the worksheet, we calculate the "real score", $\mathrm{P}_{\mathrm{rI}}$, and the "maximum possible score", $\mathrm{P}_{\mathrm{mI}}$. For the worksheet "I-Lighting", $\mathrm{P}_{\mathrm{rI}}$ and $\mathrm{P}_{\mathrm{mI}}$ are the sum of the scores obtained for each indicator, using the following formulas:

For cell "K30" the formula is

$$
=\mathrm{SUM}(\mathrm{K} 15: \mathrm{K} 29)
$$

and for cell "L30" the formula is

$$
=\operatorname{SUM}(\mathrm{L} 15: \mathrm{L} 29)
$$

The safety level $\mathrm{N}_{\mathrm{SI}}$ of the worksheet "I-Lighting" is determined as the ratio between the "real score" obtained, $\mathrm{P}_{\mathrm{rI}}$, and the "maximum possible score", $\mathrm{P}_{\mathrm{mI}}$, considered as a percentage, using the following formula for cell "D34":

$$
=(\mathrm{K} 30 / \mathrm{L} 30) \times 100
$$

The rating for the safety level, $\mathrm{N}_{\mathrm{sI}}$, is calculated using the worksheet "NS Ratings", through the logical function IF reiterated, using the following syntax for cell "C 36 ":

$$
\begin{aligned}
& =\mathrm{IF}\left(\mathrm{D} 34>\text { 90,'NS Ratings'!B9, IF(D34 > 80,'NS Ratings' } ! \mathrm{B} 10, \mathrm{IF}\left(\mathrm{D} 34>70,{ }^{\prime} \mathrm{NS}\right.\right. \\
& \text { Ratings'!B11, IF(D34 > 60,'NS Ratings'!B12, IF(D34 > 50,'NS Ratings'!B13, 'NS } \\
& \text { Ratings'!B14))))) }
\end{aligned}
$$

Thus we obtain a rating shown in Figure 1, Column "B".

For each of the worksheets corresponding to the sections: "General Risks", "Specific Risks", and "Assessment of Occupational Health and Safety Management", we proceed in a similar manner, thus being able to obtain ratings for the safety level.

\section{Discussion}

The average level of safety for the analyzed workplace is obtained by calculating the ratio between the sum of safety levels for all worksheets and the total number of worksheets, as a percentage.

After completing all worksheets with the awarded score, the real score obtained, and the safety level, we analyze the number of people exposed, the exposure time, and the severity of the consequences for each source of risk. Finally, we draw the chart for consequences and exposure, by placing the detected risks in one of the two categories: acceptable or unacceptable. The obtained safety level, correlated with the area where the risk fits on the chart, enables the establishment of preventive measures in ascending order of priorities, by filling the risk summary worksheet for each workplace and the summary worksheet for common risks in the workshop, department, or unit. 


\section{Conclusions}

The method for assessing the level of safety at work is intended for occupational safety assessment, by an assessor or an assessment team. It analytically evaluates the level of safety at each workplace and throughout the company before accidents occur, employing both a qualitative and quantitative approach. The method covers all types of workplaces including fixed, evolutional, and mobile.

For each of the checklists/worksheets corresponding to "General Risks", "Specific Risks", and "Assessment of Occupational Health and Safety Management", we analyze both the relevant and irrelevant indicators, thus determining the applicability of each indicator. Depending on the specific conditions of each workplace and according to legal requirements, the assessor awards scores. Then, by using certain formulas, the assessor obtains the "real score" and the "maximum possible score" for each indicator, the "real score obtained", the "maximum possible score" and the "safety level" for each checklist/worksheet. Based on the "safety level", the assessor automatically obtains, through logical functions, the rating for the safety level.

The safety level obtained, correlated with the placement of the risk in one of the two categories, acceptable or unacceptable, enables the establishment of preventive measures in ascending order of priorities, by filling the risk summary worksheet for each workplace and the summary worksheet for common risks in the workshop, department, or unit, thus determining the course of action required to implement the prevention and protection plan.

Acknowledgments: The authors gratefully acknowledge the support provided by the editors and anonymous reviewers who offered comments on this article.

Author Contributions: All of the authors contributed significantly to the completion of this manuscript, conceiving and designing the research and writing, and improving the paper. All authors have read and approved the manuscript.

Conflicts of Interest: The authors declare no conflicts of interest.

\section{References}

1. Darabont, A.; Tanase, N. Guide for Assessing the Level of Safety at Work; INCDPM Press: Bucharest, Romania, 1998.

2. Moraru, R.I.; Babut, G.B.; Cioca, L.I. Rationale and Criteria Development for Risk Assessment Tool Selection in Work Environments. Environ. Eng. Manag. J. 2014, 13, 1371-1376.

3. Torretta, V.; Rada, E.C.; Ragazzi, M.; Trulli, E.; Istrate, I.A.; Cioca, L.I. Treatment and disposal of tyres: Two EU approaches. A review. Waste Manag. 2015, 45, 152-160. [CrossRef] [PubMed]

4. Vasilescu, G.D.; Gaman, A.; Draghici, A.; Simion, S. An Efficient Integrated Method for Occupational Health and Safety Internal Auditing, Applicable to Complex Working Systems in Hydroelectric Power Generation Sector. Environ. Eng. Manag. J. 2012, 11, 1273-1280.

5. Ivascu, L.; Cioca, L.-I. Opportunity Risk: Integrated Approach to Risk Management for Creating Enterprise Opportunities. In 2014 2nd International Conference on Psychology, Management and Social Science (PMSS 2014), Pt 1; Lee, G., Ed.; Information Engineering Research Inst.: Newark, NJ, USA, 2014; Volume 49, pp. 77-80.

6. Gaman, A.; Pupazan, D.; Ilie, C. Development and Implementation of an Expert System for the Management of Crisis Events in Mining Industry. Environ. Eng. Manag. J. 2012, 11, 1331-1335.

7. Mihai-Adrian, B.-S.; Iulian, I.; Constantin, B.; Costin, D.D.; Alexandru, L.; Marian, C.A.; Costica, B. Improving safety in the workplace using checklists legal requirements. Qual.-Access Success 2017, 18, 31-34.

8. Ferreira, C.; Santos Baptista, J. The risk in choosing the method of Risk Assessment. Occup. Saf. Hyg.-Sho 2013, 1, 191-193.

9. Bao, J.; Johansson, J.; Zhang, J. An Occupational Disease Assessment of the Mining Industry's Occupational Health and Safety Management System Based on FMEA and an Improved AHP Model. Sustainability 2017, 9, 94. [CrossRef]

10. Moraru, R. I.; Babut, G. B.; Cioca, L. I. An Inventory of Environmental Risks Induced by Tailing Dams and Sytematic Mitigation Measures. In 12th International Multidisciplinary Scientific Geoconference, SGEM 2012, Vol. V; Stef92 Technology Ltd.: Sofia, Bulgaria, 2012; pp. 43-49. 
11. Zurbruegg, C.; Caniato, M.; Vaccari, M. How Assessment Methods Can Support Solid Waste Management in Developing Countries-A Critical Review. Sustainability 2014, 6, 545-570. [CrossRef]

12. Darabont, D.-C.; Moraru, R. I.; Antonov, A. E.; Bejinariu, C. Managing new and emerging risks in the context of ISO 45001 standard. Qual.-Access Success 2017, 18, 11-14.

13. Ruhl, R.; Lechtenberg-Auffarth, E.; Hamm, G. The development of process-specific risk assessment and control in Germany. Ann. Occup. Hyg. 2002, 46, 119-125. [PubMed] 